\title{
Aluga-se um Exército: \\ As implicações do uso de empresas militares privadas à democracia
}

\author{
Igor Barreto de Souza ${ }^{1}$ \\ João Pedro Oliveira dos Santos ${ }^{2}$ \\ Cristina Figueira Shah ${ }^{3}$
}

Antonella Sampaio Ribeiro ${ }^{4}$

\section{Resumo}

Este artigo tem como objetivo analisar a estrutura que possibilita a ocorrência de repetidas infrações ao Direito Internacional, em operações onde atuam empresas militares privadas (PMCs), as quais se dão em Estados contextualizados como fragilizados. Utilizando os conceitos de campo e habitus, fornecidos por Pierre Bourdieu a fim de averiguar como a legislação deixa brechas para uma atuação impune de empresas militares privadas, e cria incentivos para que atuem de forma a descumprir direitos das populações residentes dos territórios ocupados. Sustentamos, assim, que a ausência de responsabilidade jurídica é o principal fator que explica a recorrência dos atos destas firmas, quando expostas a situações similares. $E$ isto é explicado por meio da relação dialética estabelecida entre as PMCs e a legislação internacional. Assim, concluímos que as infrações cometidas não são fruto da vontade individual dos agentes, mas sim de um contexto social. Esse contexto construiu um conjunto de regras, as quais tornam permissível a execução de ilícitos quando tais companhias estão em missão.

\section{Palavras-chave: Direito Internacional - Empresas Militares Privadas - Campo.}

\footnotetext{
1 Graduando em Relações Internacionais do Instituto de Relações Internacionais na Pontifícia Universidade Católica do Rio de Janeiro. Email: ibsouza1999@pm.me.

2 Graduando em Relações Internacionais do Instituto de Relações Internacionais na Pontifícia Universidade Católica do Rio de Janeiro. Email: joaopsantos@pm.me.

3 Graduanda em Relações Internacionais do Instituto de Relações Internacionais na Pontifícia Universidade Católica do Rio de Janeiro. Email: crisf.shah@gmail.com

${ }^{4}$ Graduanda em Relações Internacionais do Instituto de Relações Internacionais na Pontifícia Universidade Católica do Rio de Janeiro. Email: ribeiroantonella@hotmail.com.
} 


\section{Abstract}

This article aims to analyze the structure that enables the observation of repeated Human Rights violations in operations that employ private military companies (PMCs), which take place in weakened states. Using the concepts of field and habitus, provided by Pierre Bourdieu, in order to observe how the legislation, which leaves gaps for unpunished action by these private military companies, and creates incentives for them to act in a manner that violates the rights of resident populations in the occupied territories. We state that: the absence of legal responsibility is the main factor that explains the recurrence of the acts of these firms, when exposed to similar situations. And this is explained through a dialectic between PMCs and international law. Thus, we conclude that the infractions committed are not the result of the individual will of the agents, but of a social context. This context built a set of rules, which make it possible to execute illicit acts when such companies are on mission.

\section{Keywords: International Law - Private Military Contractors - Field.}

\section{Introdução}

Durante os anos 1960 e 1970 o mundo se encontrou em meio a uma explosão de violência revolucionária (Connor, 1999, p.306) composta de diversos tipos de manifestações populares, as quais constituem uma série de eventos que se estendem das manifestações de Paris, em 1968, até atentados de grupos separatistas europeus em países como o ETA (Espanha), a Brigada Vermelha (Itália), e o IRA (Irlanda). (Connor, 1999, p.306 apud Kinsey, 2007, p.91). Com o passar do tempo e com o advento da globalização, foi percebido que a expansão de empresas multinacionais para regiões violentas do mundo, em que a permanência necessitou de uma estrutura especial de segurança, inexistente até então; fazendo com que executivos buscassem por companhias especializadas em tratar desse novo tipo de problema de segurança (Kinsey, 2007, p.92).

O que foi previsto por poucos, contudo, é que essa correlação de fatores fosse transformar empresas de segurança - as quais de início se resumiam ao papel de oferecer suporte logístico para atores privados, como a proteção de cargas e trabalhadores destes contratantes - em um novo tipo ator internacional (Kinsey, 2007, p.92), as Empresas Privadas de Segurança (PMCs); presentes de forma ativa em contextos de conflitos. Como é recorrente na ascensão de novos atores, novos desafios acabam por emergir. Nesse sentido, problemáticas ligadas 
à responsabilização e regulação dessas empresas foram sendo trazidas à discussão, visto que as constantes violações de Direitos Humanos perpetradas por agentes a serviço dessas empresas são alvo de controvérsia nas cortes internacionais e nacionais.

Este artigo tem como objetivo discutir acerca das inúmeras violações de direitos humanos cometidos por pessoas vinculadas à PMCs. Desse modo identificamos por meio dos conceitos de Habitus e Campo, de Pierre Bourdieu, uma característica estrutural - isto é, a ausência da possibilidade de punição por delito, junto à legitimidade que possuem para fazer uso da força - que autoriza os infratores a cometerem vários tipos de crimes.

O texto inicia-se apresentando ao leitor o conceito de "Novas Guerras" de Mary Kaldor (2012), o qual nos permite entender como se caracterizam os novos conflitos em que as PMCs estão incluídas. Então, passamos a discutir o que são as PMCs, como atuam e por que são utilizadas pelos Estados, mesmo que essas possuam um histórico de violação de Direitos Humanos utilizem de lobby para retirar a opinião pública do espaço de discussão quanto ao emprego de mercenários. Na quarta seção, intitulada "Responsabilidade de quem?" discutimos brevemente sobre a zona cinzenta do Direito Internacional, em que as empresas militares privadas atuam e, consequentemente, acaba permitindo que estas empresas não sejam responsabilizadas. Em seguida usamos os casos da Bósnia e do Iraque para ilustrarmos a argumentação feita nas seções anteriores, passando assim à conclusão do texto, onde apresentamos os pontos principais da reflexão teórica feita.

\section{Uma nova forma de fazer guerra}

O fenômeno da guerra está presente como forma de resolução de conflitos desde as civilizações mais antigas. Nesse sentido, observa-se sua ocorrência desde sociedades primitivas até as mais complexas onde o artifício da guerra foi sendo frequentemente empregado com a finalidade de se atingir um objetivo político. Esse recurso se transformou uma das principais ferramentas que o Estado usa para atingir um determinado fim. Guerras, por vezes, podem alterar o curso da história. Por esse motivo, o estudo desse fenômeno tornou-se essencial para que uma maior compreensão da humanidade.

A literatura existente nos fornece evidências de que houve um ponto de inflexão na estrutura de como a guerra passou a ser travada. Até o final do século XX é possível observar que os conflitos se davam por meio do embate entre forças 
armadas convencionais. Em outras palavras, eram as guerras regulares interestatais onde os Estados eram os atores principais dessas batalhas (Gray, 2007, p.245). No entanto, o fim da Guerra Fria trouxe uma mudança que pôde ser observada no advento das Novas Guerras (Kaldor, 2012, p.2).

A expansão do Neoliberalismo sobre as periferias globais, especialmente após a década de 1970 e posteriormente estendendo-se aos países que antes estavam sob a égide da União Soviética, causou danos a estes Estados em determinados aspectos. A reestruturação do setor de segurança e a desregulação dos mercados, em conjunto com uma fragilidade institucional dos Estados, fomentou a prática de comércio ilegal e colapsou a economia formal dessas nações (Newmann, 2004, p.176). Essa debilidade impossibilitou a resolução pacífica de conflitos e propiciou a ocorrência de guerras civis que frequentemente possuem altos índices de violação dos Direitos Humanos.

A concepção clássica da guerra, inspirada nos escritos do general prussiano Karl Von Clausewitz, postula que o embate se daria entre Estados, estes que "usariam a totalidade dos meios à sua disposição" (Clausewitz, [1832], p.78). Entre os meios que os Estados possuem para projetar sua força pontua-se a existência de tropas, profissionalizadas ou não, que pertencem a cadeia de comando e controle. Porém, com o fim da Guerra Fria, a dissolução da União Soviética e o avanço do neoliberalismo sobre o mundo é possível observar uma mudança nas formas de pensar a guerra. Uma guerra em que instituições e direitos inerentes particularmente ao Estado como o policiamento, participação em missões de peacekeeping, conflito armado, e ocupação territorial prolongada, foram entregues a agentes de mercado (Singer, 2004, p.2; Franconi 2008, p.961). Portanto, a maneira com que conflitos armados se fazem foi substancialmente alterada. Dessa forma, surge o fenômeno que Kaldor (2012, p.2) chama de "Novas Guerras".

As Novas Guerras ascendem com a reconfiguração da ordem política mundial após a dissolução da União Soviética, e o crescimento do movimento de globalização. A partir da década de 1990 há uma quebra de paradigma nas estruturas de governança do sistema internacional que gera uma mudança na própria natureza da guerra (Duffield, 2001, p.13). O avanço tecnológico acelerado formou redes transnacionais, que conectam indivíduos das mais longínquas partes do globo. No entanto, essas relações criadas não são democráticas pois excluem parte da população mundial (Kaldor, 2012, p.73). Em suma, essa diminuição das distâncias que separam os povos ocorreu de forma desigual, 
deixando muitos à margem da evolução tecnológica; especialmente os indivíduos que residem em países periféricos.

Também é válido lembrar da relação entre o setor econômico e o setor de segurança. A economia na globalização continua com mercados desregulados, fenômeno que ocorre desde a década de 1970. Porém, essa globalização econômica, notoriamente benéfica em certas áreas, causou mudanças controversas. A economia neoliberal não se adaptou em todos os Estados e acabou por gerar consequências graves. Há, portanto, o fomento a prática de comércio ilegal e o colapso da economia formal de países fragilizados (Newman, 2004, p.176). Desse modo, Newman (2004, p.177) afirma que a globalização gera maiores oportunidades de incentivos econômicos na guerra civil como resultado do comércio transnacional, legal e ilegal. Essa debilidade do Estado de conter seus próprios problemas o faz implodir em guerras civis com altos índices de violação dos Direitos Humanos.

Se por um lado a guerra convencional ocorre devido a questões territoriais, por outro as Novas Guerras se caracterizam pela fragmentação ou descentralização de um Estado, como pôde ser observado na Guerra do Iraque (Kaldor, 2012, p. 116). Por sua vez, os conflitos internos são causados por "um processo de transformação social: o surgimento de novas formas de autoridade e zonas alternativas de regulação" (Duffield, 2001, p.14). Nesses conflitos há a participação de uma diversidade de atores. Além de tropas pertencentes a Estados nacionais, observamos a presença de forças paramilitares, tropas sob o comando de organizações internacionais (como a Organização das Nações Unidas e a Organização do Tratado do Atlântico Norte), e por fim, soldados que estão agindo sob a alçada de empresas militares privadas $\left(\mathrm{PMCs}^{5}\right)$.

Essa variedade em um campo de batalha que se encontra em um território sem controle efetivo por parte de um Estado, abre brechas para que ocorram sucessivas violações de Direitos Humanos (Kaldor, 2006, p.96). Desse modo, observa-se uma falta de regulação internacional acerca das PMCs e seu pessoal, o que cria empecilhos para uma correta responsabilização dos crimes cometidos. A falta de regulação fica evidente quando à depender da classificação dada pela literatura aos PMCs, as regras para que elas sejam responsabilizadas são alteradas. A inexistência de um arcabouço jurídico internacional que possa responder questões fundamentais como enquadrar PMCs como "mercenários",

\footnotetext{
${ }^{5}$ Do inglês "private military contractors".
} 
"combatentes" ou "civis" (Janaby, 2016, p.151) dificulta a decisão de quais regras jurídicas serão aplicadas a eles. Com isso, é necessário entender a fundo o que são as PMCs, e como a lógica de mercado em que eles operam retroalimenta o ciclo de violações a direitos fundamentais.

\section{PMCs: O que são, como atuam, e por quê?}

As empresas privadas de segurança cobrem uma lacuna de segurança existente no sistema internacional (Uesseler, 2008, p.149), pois não somente operam no campo de segurança privada, mas também agem mediante contratação dos Estados na resolução de conflitos internos ou externos. Ao atuar desta forma, as empresas privadas quebram o monopólio legítimo do uso da força que Max Weber (1967-1968, p.56) postula ser exclusivo aos Estados. Essa quebra de monopólio retira do Estado o título de ser o único ator legítimo em campos de batalha (Uesseler, 2008, p.277). Desse modo a própria presença destas PMCs no campo de batalha já sinaliza um questionamento à essa legitimidade estatal de exercer força. Portanto, para observá-las de perto e analisar o momento histórico no qual se formaram, se faz necessário entender como atores privados adquiriram tamanha preponderância nesse campo da segurança internacional.

Assim, é destacado que essas empresas são compostas por antigos combatentes de forças policiais e exércitos nacionais, principalmente de países ocidentais, que, após terem sido dispensados - no âmbito dos cortes orçamentários para o setor de defesa no pós-Guerra Fria, como visto pela redução de gastos militares mundiais (Figura 1) - encontraram nesse ramo da indústria de defesa uma forma obter renda (Isenberg, 2006, p.3). Todavia, não se deve inferir que essas tropas possuem baixo grau de treinamento e especialização, ao contrário, o contingente que opera em PMCs é, em muitos casos, altamente treinado (Isenberg, 2006, p.3) - contando, inclusive, com unidades de elite. Isso torna possível que os Estados deleguem a elas tarefas complexas que anteriormente somente eram possíveis serem realizadas por meio de exércitos convencionais. 


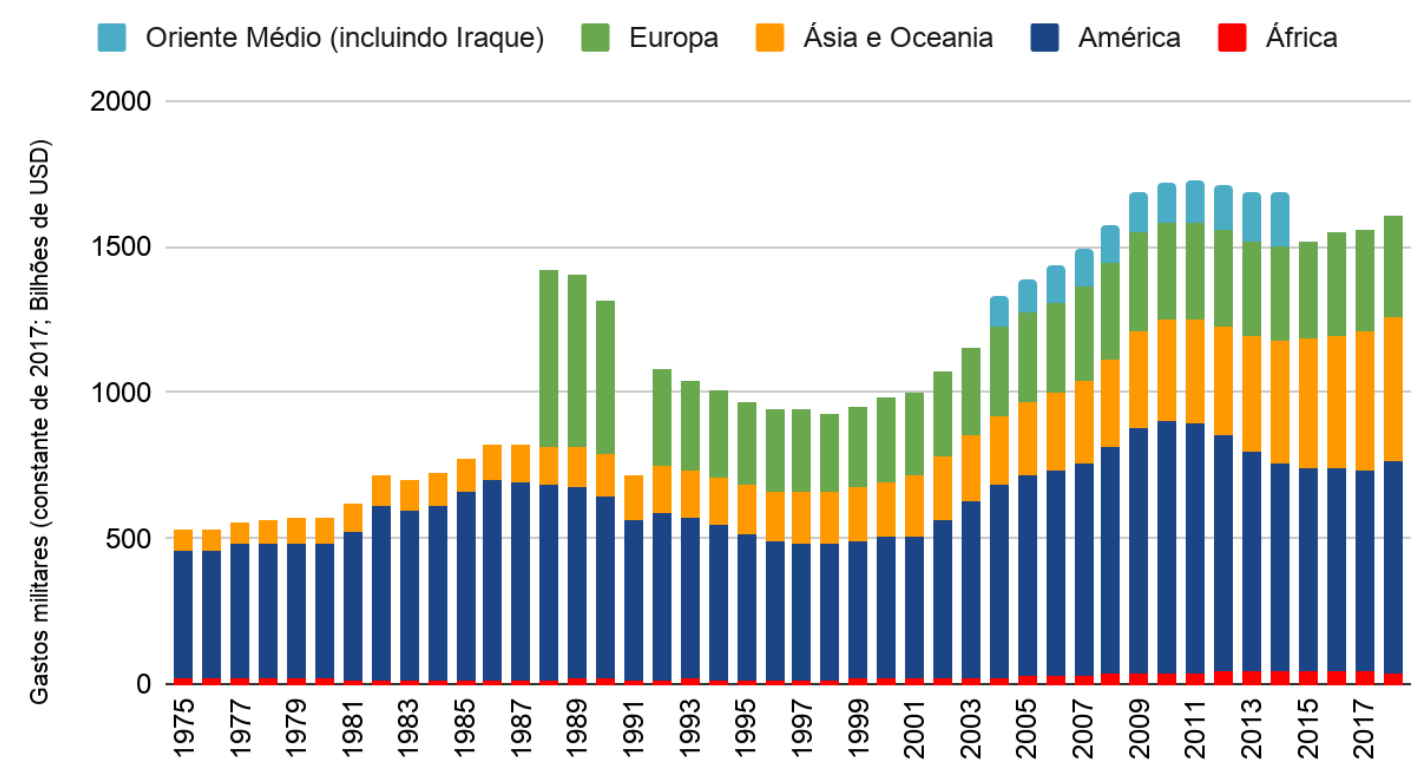

Anos

Fonte: SIPRI (2019). Elaborado pelos autores.

Porém, esse mercado não surgiu somente por necessidade de renda dos ex-combatentes, mas também por uma demanda dos Estados. Estes atores não estavam mais dispostos a arcar com os custos políticos de empreitadas militares no estrangeiro devido às mortes em batalha de tropas convencionais; algo que tem impacto negativo na opinião pública, resultando em grande desaprovação por parte da sociedade em geral (Kinsey, 2006, p.96).

Em outras palavras, é argumentado que a estratégia político-econômica adotada pelos Estados nacionais visa a diminuição da máquina pública, por meio da delegação de tarefas a setores privados. Essa estratégia, a qual discursivamente se justifica pela bandeira da diminuição de custos com aumento de eficiência, e que tem como produto o aumento do bem-estar (Starr, 1988), é responsável pelo surgimento desta indústria. A situação observada, entretanto, não fora prevista nem mesmo pelos mais fervorosos pensadores neoliberais, como Milton Friedman (Andersen, 2010), que afirmou em discursos que não 
conseguia encontrar uma forma de delegar as funções militares ao mercado privado.

Ao se tratar de PMCs, existe um conjunto de argumentos recorrentes no esforço de justificar sua utilização ao invés do emprego de forças armadas regulares. Dentre eles, cabe primeiramente citar o de que as privatizações e terceirizações teriam efeitos positivos ao orçamento público (Wulf, 2005, p.185):

No início de 2005, Prince ${ }^{6}[\ldots]$ apresentou a ideia em uma conferência militar de uma "brigada de contratados" para complementar as forças armadas oficiais. "Há uma consternação no [Pentágono] em aumentar o tamanho permanente do exército", declarou Prince. As autoridades "querem adicionar 30.000 pessoas, e conversaram sobre custos entre US $\$ 3,6$ bilhões e US $\$ 4$ bilhões para fazer isso. Bem, pela minha matemática, isso chega a cerca de US \$ 135.000 por soldado". Ele acrescentou: "Nós poderíamos fazê-lo certamente mais barato" (Scahill, 2007).

No entanto, apesar de toda uma gama de estudos acerca dos potenciais econômicos da privatização, não é possível entregar uma resposta conclusiva sobre o quanto esse fenômeno poupou ou quanto, de fato, conseguiu salvar os cofres públicos (Wulf, 2005, p.185). Pois, como afirma Singer (2004, p.10):

O uso de $\mathrm{PMFs}^{7}$ no Iraque parece ser menos influenciado por qualquer suposta economia de custos financeiros e mais por economias políticas. De fato, em muitas situações, o governo não apenas não tentou verificar se a contratação economizaria dinheiro, mas, em vez disso, criou estruturas que quase garantiam que essa economia não aconteceria (Singer, 2004, p.10).

No mundo pós-guerra fria as Empresas Militares Privadas que têm como sua maior representante a gigante norte-americana Academi ${ }^{8}$ operam em conflitos sob encomenda de governos, especialmente de países do ocidente. Porém, estas atuam de forma autônoma no campo de batalha. Em determinados momentos mais de uma PMC esteve envolvida em conflitos ao mesmo tempo. Ao observar essa coexistência em um mesmo espaço as próprias empresas se relacionam em uma espécie de jogo de poder que objetiva dominar o campo (Fernandes, 2017, p.59) em que atuam. Esse campo de atuação deve ser observado para que possamos entender como essas empresas agem quando em ação, visto que analisar a ação de PMCs isoladamente não nos permite visualizar o ambiente relacional de conflito em que se inserem.

\footnotetext{
6 "Prince" se refere a Erik Prince, "um viajante internacional, um rico empresário com contatos de alto perfil, um ex-Navy SEAL com experiência no exterior e fundador da controversa empresa de segurança privada Blackwater" (Cohen, 2018).

7 Singer utiliza o sinônimo "PMF" (Private Military Firms, ou seja, "firmas militares privadas") para se referir às "PMC" (Private Military Contractors).

${ }^{8}$ Empresa esta que inicialmente se chamava Blackwater e que também já se chamou Xe Services.
} 
Dessa forma, se analisadas como unidades, podemos observar nas PMCs um habitus, isto é, "sistemas duráveis e transponíveis de esquemas de percepção, de apreciação e de ação que resultam da instituição do social nos corpos" (Fernandes, 2017, p.45). Portanto, Habitus são formas de explicarmos regularidades comportamentais de forma não determinística, considerando fatores históricos e sociais.

Assim sendo, o conceito nos explica que há uma predisposição de um indivíduo de agir de acordo com determinadas estruturas sociais que o moldam mas, sem perder do escopo analítico a existência de uma agência individual (Power, 1999, p.48).

Assim como o Habitus, o conceito de campo é essencial para análise a ser feita (Bourdieu, 1992, p.102). Os campos não são somente o terreno em que interações ocorrem, são também "arenas de produção, circulação e apropriação de bens, serviços, conhecimentos ou status" (Swartz, 1997, p.117 apud Power, 1999, p.50) em que os atores competem em um jogo para acumular e monopolizar diferentes tipos de capital ${ }^{9}$. A metáfora do jogo utilizada por Bourdieu indica que o campo segue um conjunto de regras que definem "o impossível, o possível e o provável" (Bathmaker, 2015, p.66) a ser praticado e torna-se mais evidente em cenários em que múltiplas PMCs atuam em somente um território.

No caso das PMCs o emprego de capital de força física se faz possível por meio da demanda por parte de Estados nacionais para empresas militares atuarem em um conflito. Devido a isso, cria-se uma relação de dependência mútua entre a PMCs e o Estado que é importante, visto que o reconhecimento por parte do Estado cria uma cadeia de legitimação (Bourdieu, 1986a, p.824) que remove os atos perpetrados por atores privados do campo da violência arbitrária.

No momento em que um Estado contrata uma empresa militar, há uma obtenção de capital de força física (Bourdieu, 2014, p.198) por parte dessas, garantindo à tal companhia a legitimidade do exercício da violência em determinado território. Assim a competição entre as empresas passa a ser uma disputa sobre qual delas "jogará melhor" para atingir seu objetivo de maximizar a

\footnotetext{
9 O conceito de "capital", de Bourdieu, é entendido como o acúmulo de trabalho, o qual quando apropriado por um grupo exclusivo, esses se tornam capazes de se apropriar da energia social na forma de trabalho reificado ou vivo (Bourdieu, 1986b, 15). Nesse sentido, o autor coloca que o processo de estabelecimento de um capital se dá pela exclusão do outro que não o disponha (Bourdieu, 2014, 198). Em nossa análise, faremos uso do conceito de "capital de força física", o qual se funda a partir da "desmobilização da violência cotidiana" (Bourdieu, 2014, p.199); ou seja, a criação e legitimação de uma força militar convencional, segundo Bourdieu, se deu pela exclusão daqueles que não detinham da legitimidade para o exercício legal da força. $E$ desse modo, dada a existência de PMCs, essas estariam disputando com os outros atores no campo o acúmulo desse capital de força física.
} 
capacidade de imposição de força. Logo, se a história nos mostra que PMCs por diversas vezes violaram os Direitos Humanos, ela também nos mostra que há uma predisposição das mesmas em repetir essas infrações (DeWinter-Schmitt, 2011), tendo em vista a falta de regulação.

A escolha da empresa militar privada que irá atuar em determinado conflito, contudo, não é feita arbitrariamente. A tentativa de obter a concessão de legitimidade para atuar em determinado território por parte das PMCs tem forte fator político-institucional. Isso ocorre uma vez que as contratações são feitas por meio de processos políticos altamente influenciados por lobbies dessas empresas. Ademais, na maioria dos casos, tais pressões sobre os governos são pagas com o uso do dinheiro que as empresas adquirem em missões à serviço do Estado. $A$ opinião pública é suprimida em prol de interesses privados de empresas cujos contratos são pagos com dinheiro que, primariamente, advém do caixa estatal (Singer, 2004, p.11).

É possível afirmar que os lobbies das PMCs obtiveram sucesso em seus objetivos tanto em disseminar o uso dessas empresas militares quanto para o afastamento da opinião pública da discussão. Visto que, há mais de 60 companhias operando nesse mercado, com mais de 20.000 pessoas desempenhando funções que até então eram restritas a militares (Singer, 2004, p. 4; Isenberg, 2006, p.6). Sendo o Iraque o maior laboratório dessas experiências e onde, de acordo com Singer (2004, p.4), estaria bem mais estabelecido o comprometimento da indústria militar privada.

Percebe-se também que muitos Estados fazem uso de PMCs com o objetivo de implementar suas políticas externas e militares (Isenberg, 2006, p.19), de forma a isentar-se dos riscos decorrentes dessa atuação externa. Por um lado, "isso pode ser uma vantagem pois possibilita o governo atender necessidades estratégicas não reconhecidas, ou não apoiadas, mas pode desconectar o público de suas próprias políticas externas" (Singer, 2004, p.10).

Nesse sentido, é possível que governos contornem os controles democráticos - como o Congresso - visto que ao utilizarem PMCs são capazes de colocarem em prática missões que, caso fossem feitas com tropas regulares, necessitariam de autorização parlamentar. Esse emprego de PMCs caracteriza, portanto, um mecanismo de limitação democrática, o qual possibilita aos governos atenderem necessidades estratégicas não reconhecidas como legítimas pela opinião pública (Singer, 2004, p.10), excluindo-a, assim, das discussões. 
Essa supressão da opinião pública, portanto, se faz essencial para que o uso de PMCs seja continuado. As preferências do eleitor são centrais para a democracia $^{10}$ e há evidências de que a opinião pública possui influência nas decisões de políticas públicas (Page; Shapiro, 1983, p.177), e que o eleitor quando possui acesso a punir o constituinte que não segue suas preferências, o faz (Ferraz; Finan, 2008, p.744). Porém, se não há debate público, isto é, se o processo decisório é feito a portas fechadas, resta ao cidadão poucas formas de controlar as ações do Estado.

Esse descolamento entre sociedade e política externa, propiciado pela ação das PMCs junto à característica neoliberal de desregulamentação de mercados, criam um cenário adverso no que tange à forma como essas PMCs são responsabilizadas por seus atos. Esse mercado global de segurança opera no que Singer (2004, p.11) e Franconi (2008, p.962) nomeiam de "área cinza", isto é, um vácuo legal que não coloca limitações às ações destas empresas, nem a quem pode contratar seus serviços.

\section{Responsabilidade de quem?}

Quando constatado o vácuo legal em que essas empresas se inserem, são levantados uma série de questionamentos jurídicos. Enquanto a Declaração Universal de Direitos Humanos (Nações Unidas, 2009, p.15-16) coloca no seu artigo 29 que "todos possuem obrigações com a comunidade", é incerto o alcance das obrigações sobre os atores privados. A jurisdição internacional interpreta que um Estado não pode ser considerado responsável pelas ações de agentes privados, mesmo que estes estejam sob contrato daqueles, visto que os atos de soldados de PMCs são vistos como ações de indivíduos sem relação formal com o Estado. Alguns autores, como Palmer (2018, p.10), afirmam que as empresas militares de segurança estão totalmente fora do alcance da lei internacional.

Com isso, torna-se possível afirmar que a legislação internacional não abrange tais empresas, algo que fica claro ao observarmos que nenhum Estado foi punido por conta de um ilícito cometido por uma PMC contratada. Por mais que tenham ocorrido tentativas de definir PMCs como mercenários, por meio do Protocolo Adicional de 1977 da Convenção de Genebra, ou da Convenção sobre Mercenários de 1989, todas as empreitadas não obtiveram sucesso por conta do

\footnotetext{
${ }^{10}$ ver Dahl (1956).
} 
papel vital que esses contratados atingiram nas operações militares dos Estados (Isenberg, 2006, p.19).

Dado esse contexto, tropas de PMCs não podem ser consideradas mercenários pois a convenção que regularizaria suas ações como práticas mercenárias nunca entrou em vigor. Entretanto também não são consideradas combatentes, visto que não estão legalmente vinculados a nenhum Estado. Como salientado por (Kinsey, 2008, p.2), esse status controverso é explorado por Estados de maior poderio econômico, que não só resistem em classificá-las quando estão defendendo seus interesses, mas como instrumentalizam essa indefinição a fim de utilizá-la quando veem necessidade de força militar extra para manutenção de poder (Kinsey, 2008, p.13).

Percebe-se então que, se os campos são regidos por regras do jogo, o campo da Segurança Internacional tem uma brecha na legislação que é explorada pelos PMCs e pelos Estados que as empregam. Os danos dessa escassez de regras, as quais deveriam guiar a ação das empresas dentro do campo, e também sancionar aqueles que quebram as regras de forma explicita (Brandao, 2010, p.5), tem como resultado abusos e crimes cometidos por estas.

\section{Os casos da Bósnia e do Iraque.}

Entre as situações nas quais abusos cometidos por PMCs tornaram-se públicos, destacamos dois casos emblemáticos: o primeiro é o de tráfico de mulheres e menores que ocorreu na Bósnia, envolvendo a empresa DynCorp; o segundo é o caso da praça Nisour, localizada no Iraque, efetuado por agentes a serviço da então chamada Blackwater.

O caso bósnio ocorrido nos anos 1990, expôs a vulnerabilidade dos civis quando em área de combate que conte com a presença de empresas militares privadas. Sob a alçada da OTAN, que por sua vez obteve autorização da ONU para agir naquela situação, a PMCs atuaram em território bósnio com um contingente de 14.000 soldados (Stanley, 2015, p.77) - quantidade muito próxima a quantidade de forças regulares norte-americanas na mesma missão. Contudo, descobriu-se posteriormente que os agentes da DynCorp, em uma ação em conjunto com a máfia sérvia e a polícia da ONU, estiveram envolvidos na compra e venda de armas ilegais, mulheres e crianças, falsificação de documentos de imigração e outros ilícitos (O'Meara, 2002, p.1). O denunciante, Ben Johnston, que trouxe o caso à público, foi imediatamente demitido, enquanto ainda estava em solo bósnio, fugindo do país mediante ameaças. Assim como 
Johnston, Kathryn Bolkovac, componente da força policial das Nações Unidas que fez alegações semelhantes também fora demitida (O'Meara, 2002). A DynCorp, quando questionada sobre o caso, afirma que conduziu uma investigação interna e, de maneira semelhante, demitiu outros cinco empregados acusados devido a atividades ilegais antes mesmo das acusações de Johnston.

Mas os agentes não foram punidos pela lei. O crime não foi processado na Bósnia devido ao acordo de Dayton, o qual não permite que o governo bósnio processe nenhum cidadão norte-americano, civil da ONU ou qualquer contratado sob a lei da Bósnia, os garantindo imunidade (House of Committee, 2002, p.48). Sob a lei dos Estados Unidos, o Departamento da Justiça determinou que os casos não estavam na jurisdição norte-americana e, portanto, não poderiam ser processados. Com a aprovação do Military Extraterritorial Jurisdiction Act (MEJA), em novembro de 2000 , seria possível levar os agentes a corte norte-americana. O MEJA permitia que civis que estiverem trabalhando para o Departamento de Defesa fossem processados pela Jurisdição Criminal Federal. E isso permitiria que as companhias fossem processadas pela lei americana. Mas não foi feito mesmo com vários pedidos por meio do Freedom of Information Act $^{11}$ ao governo norte-americano para processar americanos que estavam servindo no exterior por crimes relacionados ao tráfico (House of Comittee, 2002, p.22). Tanto Johnston, como Bolkovac processaram a DynCorp posteriormente devido rescisão indevida, com ambos ganhando nos seus casos. No caso da Bolkovac, o tribunal decidiu que a DynCorp violou o "Whistleblower law"12, e a empresa foi obrigada a pagar 110,000 libras esterlinas (Barkham, 2002). A DynCorp permaneceu com o contrato com os EUA.

No caso ocorrido no Iraque, em 2007, testemunhas afirmam que um comboio da Blackwater abriu fogo durante 15 minutos em direção à população iraquiana que se encontrava na praça de Nisour, em Bagdá. $O$ atentado resultou na morte de 17 civis, com outros 20 sendo feridos. Apesar da Blackwater afirmar que o comboio tenha sido atacado primeiro, evidências e testemunhas sustentam

\footnotetext{
11 O Freedom of Information Act (FOIA Improvement Act of 2016; 5 U.S.C. § 552), é a lei norteamericana que concede ao cidadão o direito de fazer pedidos de informação ao Governo dos Estados Unidos. Por meio dela, o requerente pode solicitar acesso a arquivos, desde que não sejam confidenciais, de qualquer agência do governo estadunidense. Vale notar que a aprovação de pedidos de informação não são automáticos, e devem passar por uma avaliação feita por servidores públicos.

12 O "Public Interest Disclosure Act 1998", mais conhecido como "Whistleblower Law", garante a proteção do funcionário que relata alguma irregularidade que seja do interesse público. Ele não pode ser demitido ou tratado injustamente. A pessoa estaria protegida caso denunciasse um crime; ocorra uma ameaça a saúde e segurança de alguém; risco ou dano real ao meio ambiente; erro judiciário; violação da lei por parte da empresa; e se a pessoa acredita que alguém está encobrindo uma transgressão.
} 
a tese de que os civis estavam pacificamente reunidos, e não houve nenhum tipo de provocação (Scahill, 2008a, p.18).

Posteriormente, a PMC foi expulsa do território Iraquiano por mando do governo local. No entanto, devido à incapacidade do governo americano de garantir a segurança de seu pessoal, a empresa voltou a atuar no país (Scahill, $2008 b$, p.13). Houve um esforço por parte do governo iraquiano de responsabilizar os indivíduos. Contudo, dada a existência da Ordem $17^{13}$, que fornece imunidade civil e criminal aos PMCs, os mesmos se viram imunes a qualquer punição que fosse ser aplicada pelo governo local (Bejesky, 2014, p.70).

O único jeito de julgar os agentes da Blackwater seria então pela corte americana, devido ao MEJA. Mas por conta da dicotomia entre seu status duvidoso de civis ou combatentes, não foi o meio utilizado. Houve então a atualização do Uniform Code of Military Justice (UCMJ) em 2007, que anteriormente deixava aplicar o código militar a todos membros militares, incluindo contratados no caso de guerra declarada pelo Congresso. Com a atualização, o código passou a ser aplicado não somente no caso de guerra declarada, mas também em operações de contingência (Palmer, 2018, p.17)

Embora houvesse essa mudança, ainda havia problemas em aplicar o código às PMCs. Primeiro porque a UCMJ é baseada em uma cadeia de comando militar tradicional, o que dificilmente ocorre com os PMCs. Em segundo lugar, uma grande quantidade de empregados pela PMCs não pode ser sujeitada aos procedimentos da corte marcial norte-americana por não serem americanos (Palmer, 2018, p.22). Isso cria lacunas na política doméstica, pois o assunto não é discutido publicamente nem resolvido em sua totalidade. O caso da praça foi uma exceção, pois os quatro agentes no comboio da Blackwater eram americanos, o que permitia o processo pela corte estadunidense. Além disso, no fim, o que permitiu que os agentes fossem julgados foram leis que não envolviam e não eram intencionadas para a regulação da indústria de PMC. Segundo o The Guardian (Woolf, 2015), eles foram julgados por um estatuto no qual aqueles que cometeram ofensas fora da jurisdição de qualquer estado ou distrito, poderia ser julgado no distrito residencial do réu, ou o distrito de Columbia.

No primeiro julgamento, em 2009, o caso foi dispensado depois que o juiz achou uma falha na fase de reunião de provas pela acusação. A Corte argumentou

${ }^{13}$ A "Coalition Provisional Authority Order Number 17" é uma legislação emitida pela Autoridade Provisória da Coalizão, que governou o Iraque entre 2003-2004 que legisla acerca do "status da coalizão [de ocupação do Iraque], foreign liaison missions, seu pessoal e contratantes" (Coalition Provisional Authority, 2007, p.1, Tradução nossa). 
que as acusações precisavam ser retiradas pois as declarações dos réus foram compelidas, já que houve a ameaça da perda do emprego. O caso voltou em 2011, quando a corte anulou a decisão inicial de que os erros eram substanciais o suficiente para descartar as acusações. Então, três dos envolvidos foram condenados a pelo menos 30 anos de prisão e o quarto, que foi o primeiro a disparar, Nicholas A. Slatten, recebeu prisão perpétua (Palmer, 2018, p.31-33).

Em 2017, uma corte federal de apelações decidiu que uma das acusações estava incorreta. A acusação vinha de uma lei sobre pessoas que levam armas perigosas com a intenção de executar um ato violento. Como os agentes estavam usando armas dadas pelo governo em uma zona de guerra na época do incidente, a acusação foi retirada. Foi ordenada uma nova condenação dos três acusados, podendo haver a diminuição da pena, enquanto a corte dispensou a prisão perpétua de Slatten (Palmer, 2018, p.34). No final de 2018, Slatten foi julgado novamente e considerado culpado, mas ainda não houve a condenação. Os outros três acusados ainda aguardam a condenação (The Guardian, 2018).

Verifica-se, assim, em ambos os casos, apesar de evidências claras de que empresas militares privadas estavam envolvidas em casos de amplas violações aos Direitos Humanos e do Direito Internacional, as regras vigentes não foram suficientes para proteger a população civil. A ausência de controles por parte da legislação internacional construiu um conjunto de ideias, normas e conhecimentos $^{14}$ (Pouliot, 2013, p.30) que são aceitos de forma axiomática pelas PMCs, com estas regras permitindo a execução de ilícitos por parte de seus agentes, desde que cometidos em missão.

A execução de ações que extrapolam o domínio do legal são necessárias pois as empresas militares privadas buscam o domínio do campo, que acaba sendo alcançado por meio de legitimidade - a qual advém do vínculo contratual com o Estado - ganhos materiais e a possibilidade da PMC de ser agraciada com um novo contrato com outros governos.

\section{Conclusão}

Portanto, apesar de PMCs virem se expandindo cada vez mais no setor de Segurança, os custos de utilizar esses agentes em campos de batalha são bastante altos, como analisado nos casos da Bósnia e do Iraque.

\footnotetext{
${ }^{14}$ Chamada por Bourdieu de Doxa.
} 
Nesse sentido, o objetivo deste artigo foi refletir, à luz do instrumental teórico fornecido por Pierre Bourdieu, sobre a atuação de empresas militares privadas em ambientes de guerra, quando estas são contratadas por um governo diferente daquele que, de jure, detém a jurisdição do território onde a empresa está atuando. É salientado ao longo da reflexão acerca da atuação desse tipo de empresa, a característica dialética de construção da prática, que não é de caráter racional-instrumental, nem mesmo fruto somente de uma subjetividade individual.

Dessa forma, acreditamos que as infrações cometidas por empresas militares privadas não são informadas tão somente, pela a vontade individual dos agentes em comando das mesmas. As infrações são fundamentadas, sobretudo, em um conjunto de normas sociais que foram construídas socialmente mediante a existência de uma "zona cinzenta" do Direito Internacional, a qual abre espaço para a execução de arbitrariedades, as quais não são passíveis de punições, tanto por parte das autoridades locais, quanto pelas autoridades internacionais. Esta zona cinzenta se mantém devido às vantagens militares que são fornecida aos Estados nacionais, oportunizando a projeção força extra sem o envolvimento de seus exércitos nacionais.

Portanto, por mais que haja esforços para que os agentes que cometeram delitos sejam responsabilizados de forma ad-hoc, essa terá pouca efetividade se não acompanhada de uma tentativa de mudança estrutural. Há a necessidade da criação de um arcabouço legal que altere as regras que regem o campo da Segurança Internacional, prevendo consequências legais e regras do jogo mais restritivas, para, assim, podermos esperar alguma modificação no comportamento das práticas aplicadas pelas empresas militares privadas.

Concluímos então que as PMCs usam da supressão de mecanismos de controle democrático nos Estados contratantes, e da falta de regulação internacional acerca de suas ações, para operar em um ambiente virtualmente sem lei. Entendemos que o estabelecimento de legislação internacional, que reja a situação social presente nos campo em que as PMCs atuam é uma forma de alterar as práticas executadas pelas empresas militares privadas. Assim, quebrase essa ortodoxia violenta e ilegal em que operam os contratados, um dos traços - negativos - que diferenciam o conflito clássico das novas guerras.

\section{Bibliografia}


ANDERSEN, J. Friedman's on the Military Industrial Complex. 2010. 1min 36s, son., color. Disponível em: <https://www.youtube.com/watch?v=iXMJHCXXDc\&t=13s> Acesso em: 01 Dez. 2019.

BARKHAM, Patrick. UN official who exposed sex trade wins payout. The Times (London, England), [s. I.], 2002. Disponível em: $<$ https://www.thetimes.co.uk/article/un-official-who-exposed-sex-trade-winspayout-gwhrkgm8I29>. Acesso em: 6 de Nov. 2019.

BATHMAKER, Anne-Marie. Thinking with Bourdieu: thinking after Bourdieu. Using "field" to consider in/equalities in the changing field of English higher education. Cambridge Journal of Education, v.45, n. 1, 2015, p. 61-80.

BOURDIEU, Pierre. The force of law: Toward a sociology of the juridical field. Hastings LJ, v. 38, p. 805, 1986a.

BOURDIEU, Pierre. "The forms of Capital". In: RICHARDSON, J. Handbook of Theory and Research for the Sociology of Education. (Ed.), London: Greenwood Press, 1986b, p.241-258.

BOURDIEU, Pierre. On the state: Lectures at the Collège de France, 1989-1992. Polity Press, 2014.

BRANDAO, Z. Operating with concepts: with and beyond Bourdieu. Educ. Pesqui., São Paulo , v. 36, n. 1, abr. 2010, p. 227-241. Disponível em: <http://dx.doi.org/10.1590/S1517-97022010000100003>. Acesso em: 04. Dez. 2019.

CANES-WRONE, Brandice; BRADY, David W.; COGAN, John F. Out of step, out of office: Electoral accountability and House members' voting. American Political Science Review, v. 96, n. 1, p. 127-140, 2002.

COALITION PROVISIONAL AUTHORITY. COALITION PROVISIONAL AUTHORITY ORDER NUMBER 17: STATUS OF THE COALITION, FOREIGN LIAISON MISSIONS, THEIR PERSONNEL AND CONTRACTORS. Iraque, 2007. Disponível em: https://www.usace.army.mil/Portals/2/docs/COALITION_PROVISIONAL.pdf. Acesso em: 29 nov. 2019. 
COHEN, M. Who is Erik Prince? CNN. Disponível em <https://edition.cnn.com/2018/03/08/politics/erik-prince-russia-seychelles-trumptransition/index.html>. Acesso em 26 nov. 2019.

DEWINTER-SCHMITT, Rebecca. Holding Private Security Contractors Accountable for Human Rights Abuses. Disponível em: $<$ https://blog.amnestyusa.org/us/holding-private-security-contractorsaccountable-for-human-rights-abuses/>. Acesso em: 01 abr. 2020.

DUFFIELD, Mark. Global Governance and the new wars: the merging of development and security. New York: Zed books, 2006, p. 1-15.

FERRAZ, Claudio; FINAN, Frederico. Exposing corrupt politicians: the effects of Brazil's publicly released audits on electoral outcomes. The Quarterly Journal of Economics, v. 123, n. 2, 2008, p. 703-745.

FERNANDES, António Teixeira. O campo político. Sociologia: Revista da Faculdade de Letras da Universidade do Porto, v. 16, 2017.

ISENBERG, D. A government in search of cover: PMCs in Iraq. New York: British American Security Information Council, 2006.

KALDOR, Mary. New and Old wars. 3a ed. Cambridge: Polity Express, 2012.

KINSEY, Christopher. International Law and the Control of Mercenaries and Private Military Companies. Cultures \& Conflicts. 26 jun. 2008. Disponível em: <https://journals.openedition.org/conflits/11502>. Acesso em: 29 mar. 2020.

. Private Security Companies: Agents of Democracy or Simply Mercenaries?. In: Private Military and Security Companies. VS Verlag für Sozialwissenschaften, 2007. p. 87-104.

_. Corporate soldiers and international security: The rise of private military companies. Oxon e Ney York: Routledge, 2006. 196p.

NAÇÕES UNIDAS. Declaração Universal dos Direitos Humanos. Disponível em: <https://nacoesunidas.org/wp-content/uploads/2018/10/DUDH.pdf>. Acesso em: 02 dez 2019. 
NEWMAN, Edward. The New wars debate: a historical perspective is needed. Oslo: International Peace Research Institute, 2004.

O'MEARA, K. P. DynCorp Disgrace. (cover story). Insight on the News, [s. I.], v. 18, n. 4, p. 12, 2002. Disponível em: <https://www.questia.com/magazine/1G182651659/dyncorp-disgrace-employees-of-the-corporation-have>. Acesso em: 24 nov. 2019.

PAGE, Benjamin I.; SHAPIRO, Robert Y. Effects of public opinion on policy. American political science review, v. 77, n. 1, 1983, p. 175-190.

PALMER, J. 'War For Sale: The Case of Blackwater Unaccountable Private Military Companies in Iraq and Afghanistan'. All Regis University Theses, Denver: n.859, 2018.

POULIOT, Vincent et al. Bourdieu's concepts: Political sociology in international relations. In: ADLER-NISSEN, Rebecca (ed.). Bourdieu in International Relations: Rethinking key concepts in IR. New York: Routledge, 2013, p. 24-45. $245 p$.

POWER, Elaine M. An Introduction to Pierre Bourdieu's Key Theoretical Concepts. Journal for the Study of Food and Society, v. 3, n. 1, 1999, p. 48-52.

SCAHILL, Jeremy. Blackwater: a ascensão do exército mercenário mais poderoso do mundo. São Paulo: Companhia das Letras, 2008a. 548 p.

Blackwater: The Rise of the World's Most Powerful Mercenary Army. Bold Type Books, 2008b. 560p.

_. Bush's rent-an-army. Los Angeles Times. Disponível em <https://www.latimes.com/archives/la-xpm-2007-jan-25-oe-scahill25-story.html>. Acesso em 10 jun. 2019.

SINGER, Peter. The private military industry and Iraq: what have we learned and where to next? <https://www.files.ethz.ch/isn/14132/PP4_Singer.pdf>. Acesso em: 10 Jun. 2019. STANLEY, B. E. Outsourcing Security: Private Military Contractors and U.S. Foreign Policy. Lincoln, NE: Potomac Books, 2015. 
STARR, Paul. The meaning of privatization. Yale Law and Policy Review. 6, 1988. Disponível em: <https://www.princeton.edu/ starr/articles/articles8089/Starr-MeaningPrivatization-88.htm>. Acesso em: 26 Nov. 2019.

STOCKHOLM INTERNATIONAL PEACE RESEARCH INSTITUTE. World military expenditure grows to $\$ 1.8$ trillion in 2018. 29 de abril de 2019. Disponível em: <https://www.sipri.org/media/press-release/2019/world-militaryexpenditure-grows-18-trillion-2018>. Acesso em: 22 Nov. 2019.

THE GUARDIAN. Former Blackwater guard convicted for 2007 massacre of civilians in Baghdad. Washington, 19 de dezembro de 2018. Disponível em: www.theguardian.com/world/2018/dec/19/former-blackwater-guard-guilty-2007massacre-baghdad. Acessado em 09/07/2019.

UESSELER, Rolf. Guerra como prestação de serviços: a destruição da democracia pelas empresas militares privadas. São Paulo: Estação Liberdade, 2008.

UNITED STATES. CONGRESS. HOUSE. COMMITTEE ON INTERNATIONAL RELATIONS. SUBCOMMITTEE ON INTERNATIONAL OPERATIONS AND HUMAN RIGHTS. The U.N. and the sex trade in Bosnia: isolated case or larger problem in the U.N. system?: hearing before the Subcommittee on International Operations and Human Rights of the Committee on International Relations, House of Representatives, One Hundred Seventh Congress, second session, April 24, 2002. [s. I.], 2002. Disponível em: $<$ https://babel.hathitrust.org/cgi/pt?id=pur1.32754073712436\#?>. Acesso em: 6 de Nov. de 2019.

UNITED KINGDOM. Public Interest Disclosure Act 1998. UK Public General Acts. $1998 . \quad$ Disponível em: <http://www.legislation.gov.uk/ukpga/1998/23/contents>. Acesso em: 28 de Mar. de 2020.

VON CLAUSEWITZ, Carl. Da guerra. WWF Martins Fontes, 2017.

WEBER, Max. A política como vocação. In: WEBER, Max. Ciencia e Política: duas vocações. Berlim: Dunker \& Hunblot, 1967-1968, p. 55- 124. 
WOOLF, N. Former Blackwater guards sentenced for massacre of unarmed Iraqi civilians. The Guardian, 2015. Disponível em:

<https://www.theguardian.com/us-news/2015/apr/13/former-blackwater-guardssentencing-baghdad-massacre>. Acesso em 09 Jul. 2019.

WULF, Herbert. Internationalizing and Privatizing War and Peace. Nova York: 2005. 263p. 